\title{
Proteínas séricas de potros da raça Puro Sangue Árabe recém-desmamados ou com mais de trinta dias de desmame ${ }^{1}$
}

\author{
Diego Horcajo Martinez Fudoli Favero², Deborah Penteado Martins Dias², Walter \\ Heinz Feringer-Junior ${ }^{2}$, Nara Saraiva Bernardi ${ }^{2}$ e José Corrêa de Lacerda-Neto ${ }^{2 *}$
}

\begin{abstract}
Favero D.H.M.F., Dias D.P.M., Feringer-Junior W.H., Bernardi N.S. \& Lacerda-Neto J.C. 2011. [Serum protein profile in Arabian foals recently weaned or at more than thirty days after weaning.] Proteínas séricas de potros da raça Puro Sangue Árabe recém-desmamados ou com mais de trinta dias de desmame. Pesquisa Veterinária Brasileira 31(Supl.1):89-93. Departamento de Clínica e Cirurgia Veterinária, Faculdade de Ciências Agrárias e Veterinárias, Universidade Estadual Paulista, Via de acesso Prof. Paulo Donato Castellane s/n, Jaboticabal, SP 14884-900, Brazil. E-mail: jlacerda@fcav.unesp.br

The perinatal phase of foal development is one of the most challenger period for the immune system. The present study has analyzed serum protein profile, considering variables related to immunity in foals at the perinatal phase, verifying passive immunity transfer. The group 1 (G1) contained eight foals evaluated one day after weaning, and group 2 (G2) included twenty foals at more than thirty days after weaning. Total protein concentration was determined by means of refractometry. The concentration of serum proteins was determined through sodium dodecyl sulphatepolyacrylamide gel electrophoresis. Results were submitted to analysis of variance and Tukey test $(\mathrm{P}<0.05)$. IgA concentration showed difference $(\mathrm{P}<0.05)$ between the two studied groups, however data were within adult healthy horses normal values. IgG didn't show statistical difference $(P>0.05)$. The cellular immunity establishment occurs in the neonatal phase, in foals that suckled colostrum and milk properly. The present study showed differences in serum protein profile, considering variables related to immunity, in foals immediately after weaning comparing to foals at more than 30 days after weaning. According to the observed values, we conclude that foals, even early weaned, showed proper passive immunity tranfer.
\end{abstract}

INDEX TERMS: Arabian foals, electrophoresis, neonatology, serum proteins, weaning.

RESUMO.- A fase perinatal do desenvolvimento constitui um dos períodos de vida mais desafiadores para o sistema imunológico dos potros. $\mathrm{O}$ objetivo do presente estudo foi verificar o perfil protéico sérico de parâmetros relacionados à imunidade de equinos jovens no período perinatal, verificando-se a transferência de imunidade passiva. Oito animais desmamados há um dia, formaram o Grupo 1 (G1), enquanto vinte animais desmamados há mais de trinta dias formaram o Grupo 2 (G2). A concentração sérica de proteína total foi determinada por refratometria. Para o fracio-

\footnotetext{
${ }^{1}$ Recebido em 8 de setembro de 2011.

Aceito para publicação em 12 de dezembro de 2011.

${ }^{2}$ Departamento de Clínica e Cirurgia Veterinária, Faculdade de Ciências Agrárias e Veterinárias (FCAV), Universidade Estadual Paulista (Unesp), Via de Acesso Prof. Paulo Donato Castellane s/n, Jaboticabal, SP 14884900, Brasil.*Autor para correspondência: jlacerda@fcav.unesp.br. Demais autores: diegofavero_metra@hotmail.com, deborah_dias@hotmail.com, walterferinger@hotmail.com, nara.sb@gmail.com
}

namento das proteínas, utilizou-se eletroforese em gel de acrilamida. Os resultados obtidos foram submetidos à análise de medidas repetidas e ao teste Tukey $(\mathrm{p}<0,05)$ para comparação das médias. As concentrações de IgA apresentaram diferença $(\mathrm{p}<0,05)$ entre os grupos, porém os valores observados encontravam-se dentro do considerado normal para equinos adultos. Não houve diferença $(p>0,05)$ nas concentrações de IgG. 0 estabelecimento adequado da imunidade celular ocorre durante a fase neonatal, nos animais que ingerem adequadamente o colostro e o leite. 0 presente estudo determinou diferenças no perfil protéico sérico de parâmetros relacionados à imunidade de equinos jovens no período imediato ao desmame, comparados com animais desmamados há mais de 30 dias. De acordo com os valores observados, concluiu-se que os animais, mesmo desmamados precocemente, obtiveram transferência adequada de imunidade passiva. 
TERMOS DE INDEXAÇ̃̃O: Potros árabes, eletroforese, neonatologia, proteínas séricas, desmame.

\section{INTRODUÇÃO}

Durante os primeiros meses de vida, os neonatos são submetidos a desafios e sofrem diferentes adaptações fisiológicas. Tais modificações, incluem a aquisição de imunidade passiva nas primeiras horas de vida pelo contato com o ambiente, a modulação da imunidade ativa durante os primeiros meses, o desenvolvimento dos tecidos e líquidos pulmonares para permitir a respiração imediatamente após o parto, a adequação do sistema digestório à condição de lactente e posteriormente à de herbívoro e, a exposição do sistema musculoesquelético às forças de impacto (Frey Jr 2006).

Os equinos apresentam deficiência imunológica ao nascer, uma vez que quase não possuem imunidade humoral e a imunidade de origem celular não está suficientemente estabelecida (Morris 1986, Scotoni \& Neto 1991). A transferência intra-uterina de imunoglobulinas maternas para o feto equino é impedida devido ao tipo de placentação que a égua apresenta, a placentação epiteliocorial difusa, que atua como barreira à passagem de grandes moléculas. Portanto, antes de ingerir o colostro, o potro apresenta concentrações insuficientes de imunoglobulinas (Koterba et al. 1990, Jainudeen \& Hafez 1995), sendo a transferência passiva via colostro fundamental na proteção contra infecções no período neonatal (LeBlanc et al. 1992). 0 colostro ainda provém fatores de crescimento (Stelwagen et al. 2009).

A concentração de proteínas séricas de animais neonatos pode variar por influência de alguns fatores, dentre os quais se destacam a ingestão de colostro e a idade. Ao nascimento, potros exibem baixos teores protéicos e, após receberem o colostro, apresentam aumento no total das proteínas devido à absorção intestinal de macromoléculas, incluindo as imunoglobulinas (Butler 1969, Feldman et al. 2000). Segundo Raidal et al. (2005) há a necessidade da ingestão do colostro ainda nas primeiras doze horas após o parto devido a modificações que o epitélio intestinal sofre após esse período, ocorrendo drástica redução na capacidade de absorção das imunoglobulinas contidas no colostro. Quantidade suficiente de colostro e leite deve ser produzida para assegurar o crescimento e desenvolvimento saudável (Chavatte 1997). As imunoglobulinas presentes no colostro são principalmente IgG, IgM e IgA (Rumbough et al. 1979, Koterba et al. 1990). As IgG são as mais abundantes, estando entre $65 \%$ e $90 \%$ das imunoglobulinas totais, com concentração total variável de 2.050 a $7.650 \mathrm{mg} / \mathrm{dL}$. Os níveis de IgM e IgA variam de $100-350 \mathrm{mg} / \mathrm{dL}$ e $500-1.500 \mathrm{mg} / \mathrm{dL}$, respectivamente (Tizard 2002). Segundo Kuhl et al. (2011), a concentração de gamaglobulinas séricas em potros é baixa ao nascimento, alcança seu máximo valor logo após a ingestão do colostro e decresce continuamente nas quatro primeiras semanas de vida. Neste período, a concentração volta a subir pois o potro começa a sintetizar as moléculas de gamaglobulina. Portanto, não se observa falha imunológica em animais que ingeriram adequadamente o colostro. A falha na transferência de imunidade passiva é caracterizada quando o nível de IgG é inferior a $400 \mathrm{mg} / \mathrm{dl}$ e a falha parcial quando os níveis estão de 400-800mg/dL. A transferência é adequada quando alcançados níveis séricos superiores a $800 \mathrm{mg} / \mathrm{dL}$ (Rumbaugh et al. 1979, Mellor \& Stafford 2004, Kenzig et al. 2009).

Pelo significado biológico e múltiplas funções exercida no sistema orgânico, a avaliação dos níveis séricos das proteínas totais e de suas frações (albumina, alfaglobulinas, betaglobulinas e gamaglobulinas) obtidas por eletroforese, representa um importante auxílio ao diagnóstico clínico (Kaneko et al. 1997). Na rotina clínica, considera-se importante minimizar a quantidade de sangue coletado de neonatos, especialmente quando apresentam enfermidades. A mensuração de proteínas plasmáticas por eletroforese permite que todos os testes diagnósticos necessários, sejam realizados a partir de uma amostra de sangue (Paltrinieri et al. 2008).

Duas fases importantes de desenvolvimento são descritas em potros no período transcorrido entre o nascimento e o desmame: a neonatal, que se inicia ao nascimento e se estende até que o animal complete o primeiro mês de vida e, a perinatal, de maior duração, que se prolonga até o momento que o potro é separado da mãe (Rossdale \& Ricketts 1979). Estudos sobre o sistema imunológico foram realizados no período neonatal (Knottenbelt et al. 2004, Paltrinieri et al. 2008, Kuhl et al. 2011). Porém há poucos relatos referentes à avaliação imunológica de potros no período perinatal, em particular envolvendo animais desmamados precocemente.

Em que pese a contribuição da espécie equina para a economia nacional, traduzida por movimentação econômica da ordem de $\mathrm{R} \$ 7,3$ bilhões por ano e a ocupação direta de cerca de 640 mil pessoas, cifra que poderia atingir a casa de $\mathrm{R} \$ 3,2$ milhões se forem incluídos os empregos indiretos (Lima et al. 2006), poucos estudos foram realizados visando avaliar a imunidade durante um período de tal importância na vida dos equinos, o desmame, o qual quando mal conduzido, pode causar prejuízos importantes. Diante dos fatos assinalados, o objetivo deste estudo foi verificar o perfil protéico sérico de parâmetros relacionados à imunidade de equinos jovens, no período perinatal, imediatamente após o desmame ou com mais de trinta dias de desmame, verificando-se a transferência de imunidade passiva.

\section{MATERIAL E MÉTODOS}

O protocolo experimental realizado no presente estudo está de acordo com os princípios éticos adotados pelo Colégio Brasileiro de Experimentação Animal (COBEA) e foi aprovado pela Comissão de Ética no Uso de Animais (CEUA) da Faculdade de Ciências Agrárias e Veterinárias/Unesp, Campus de Jaboticabal (Protocolo $\mathrm{n}^{\circ}$ 019693-11).

Foram utilizados 28 potros da raça Puro Sangue Árabe, machos, entre 3 e 14 meses de idade, provenientes do mesmo criatório e sob o mesmo manejo. As éguas apresentavam escore corporal entre 5 e 6, segundo a escala determinada por Henneke et al. (1983). Durante todo o período gestacional, período neonatal e após o desmame, éguas e potros permaneceram em regime extensivo de criação, alojados em piquetes de capim Tifton $(\mathrm{Cy}$ nodon dactylon). Durante o aleitamento, as éguas receberam 1 $\mathrm{kg}$ de ração concentrada por kg de peso vivo. Formaram-se dois grupos (G) de potros, de acordo com o período de desmame. Oito 
potros machos desmamados há 1 dia, entre 3 e 5 meses de idade e peso médio de $151 \pm 22 \mathrm{~kg}$, formaram o G1. 0 G2 foi formado por vinte potros machos desmamados há mais de 30 dias, entre 6 e 14 meses de idade e peso médio de $302 \pm 128 \mathrm{~kg}$. Os animais apresentavam-se hígidos, de acordo com exame clínico previamente realizado (Taylor \& Hillyer 1997). Foram avaliados os seguintes parâmetros: frequência cardíaca, frequência respiratória, murmúrio vesicular e motilidade intestinal por auscultação; temperatura retal mensurada por termômetro digital; coloração das mucosas oral e conjuntival e, presença de secreções ocular e nasal determinadas por inspeção; tempo de preenchimento capilar da mucosa oral, determinado por compressão digital seguida de observação do tempo em segundos do reestabelecimento da vascularização; turgor cutâneo, consistência e sensibilidade de linfonodos submandibulares e retrofaríngeos determinados por palpação; consistência e coloração das fezes determinadas por palpação e inspeção visual das mesmas.

Realizou-se colheita de sangue venoso utilizando-se sistema a vácuo, em tubos com volume de aspiração de $10 \mathrm{~mL}$ sem aditivo, por meio de venipunção jugular empregando-se agulha hipodérmica. As amostras de sangue foram centrifugadas a $3000 \mathrm{rpm}$ por 15 minutos, à temperatura de $22^{\circ} \mathrm{C}$, o soro foi separado e armazenado em tubos devidamente identificados, congelado e armazenado à temperatura de $-5^{\circ} \mathrm{C}$ até o momento da análise.

Os métodos disponíveis para avaliação dos níveis séricos de imunoglobulinas incluem os indiretos (refratometria, turbidez pelo sulfato de zinco, coagulação por glutaraldeído, aglutinação no látex) (Pfeiffer et al. 1977, Rumbaugh et al. 1979, Koterba et al. 1990, Clabough et al. 1991, Stoneham et al. 1991, Parish 1996, Raidal 1996) e os diretos (eletroforese, imunodifusão radial simples e ELISA) (Pfeiffer et al. 1977, Rumbaugh et al. 1979). A concentração sérica de proteína total foi determinada por refratometria. Para o fracionamento das proteínas, foi utilizada eletroforese em gel de acrilamida contendo dodecil sulfato de sódio (SDS-PAGE), conforme técnica descrita por Laemmli (1970). Após fracionamento o gel foi corado durante 10 minutos em solução de azul de coomassie, constituída de metanol (50\%), água (40\%), ácido acético glacial $(9,75 \%)$ e azul de coomassie $(0,25 \%)$. Em seguida, o gel foi colocado em solução de ácido acético a $7 \%$ para retirar o excesso de corante, até que as frações protéicas se mostrassem nítidas. As concentrações das proteínas foram determinadas em densitômetro computadorizado. Como referência, foram utilizadas soluções marcadoras com pesos moleculares de 29.000, 45.000, 66.000, 97.400, 116.000 e 205.000 Dalton (Da), além de proteínas purificadas - albumina, imunoglobulina G (IgG), haptoglobina, $\alpha_{1}$-antitripsina e transferrina.

Os resultados obtidos foram submetidos à análise de medidas repetidas (One way ANOVA) e, constatada a significância, as médias foram comparadas pelo teste Tukey a 5\%, utilizando-se o software SAS 9.0.

\section{RESULTADOS E DISCUSSÃO}

Relativamente aos parâmetros clínicos mensurados, estes encontravam-se dentro de valores normais para a espécie e faixa etária. Não se observou diferença $(p>0,05)$ entre os grupos, bem como entre os animais de um mesmo grupo, os quais na sua totalidade foram considerados sadios.

Os resultados obtidos para proteína total e demais proteínas do plasma sanguíneo de potros sadios da raça Puro Sangue Árabe, imediatamente após o desmame e com mais de trinta dias de desmame, encontram-se no Quadro 1. Foram determinadas as concentrações em $\mathrm{mg} / \mathrm{dL}$ de proteínas com peso molecular variando de 19.330 Dalton (Da) a
Quadro 1. Médias \pm EPM da concentração protéica $(\mathrm{mg} / \mathrm{dL})$ de potros recém desmamados (G1) e com mais de 30 dias de desmame (G2). Proteínas não identificadas indica-se PNI. 0 peso molecular apresenta-se em Daltons (Da). Médias seguidas pela mesma letra na linha não diferem entre si pelo teste Tukey $(\mathrm{p}<0,05)$

\begin{tabular}{|c|c|c|}
\hline \multirow[t]{2}{*}{ Proteínas e peso molecular (Da) } & \multicolumn{2}{|c|}{ Concentração protéica (mg/dL) } \\
\hline & $\mathrm{G} 1(\mathrm{~N}=8)$ & $\mathrm{G} 2(\mathrm{~N}=20)$ \\
\hline Proteina total & $7277,500 \pm 499,964 \mathrm{~A}$ & $7013,500 \pm 340,515 \mathrm{~A}$ \\
\hline IgA $166.000 \mathrm{Da}$ & $249,377 \pm 31,092 \mathrm{~A}$ & $197,550 \pm 43,853 \mathrm{~B}$ \\
\hline Ceruloplasmina $107.000 \mathrm{Da}$ & $8,423 \pm 1,775 \mathrm{~A}$ & $7,630 \pm 2,275 \mathrm{~A}$ \\
\hline Transferrina $86.000 \mathrm{Da}$ & $467,822 \pm 88,412 \mathrm{~A}$ & $363,127 \pm 69,098 B$ \\
\hline Hemopexina $79.000 \mathrm{Da}$ & $75,467 \pm 57,108 \mathrm{~A}$ & $70,562 \pm 14,694 \mathrm{~A}$ \\
\hline Albumina $62.000 \mathrm{Da}$ & $4025,811 \pm 268,881 \mathrm{~A}$ & $4101,274 \pm 242,913 \mathrm{~A}$ \\
\hline$\alpha 1$-antitripsina $56.000 \mathrm{Da}$ & $241,111 \pm 104,906 \mathrm{~A}$ & $178,056 \pm 57,466 \mathrm{~A}$ \\
\hline IgG de cadeia pesada $52.000 \mathrm{Da}$ & $757,101 \pm 118,895 A$ & $809,006 \pm 105,144 \mathrm{~A}$ \\
\hline 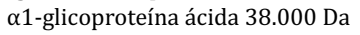 & $47,617 \pm 14,682 \mathrm{~A}$ & p25,072 $\pm 13,176 B$ \\
\hline Haptoglobina $39.000 \mathrm{Da}$ & $67,443 \pm 32,727 \mathrm{~A}$ & $48,338 \pm 24,713 \mathrm{~A}$ \\
\hline IgG de cadeia leve $26.000 \mathrm{Da}$ & $535,417 \pm 92,976 \mathrm{~A}$ & $547,225 \pm 101,665 \mathrm{~A}$ \\
\hline PNI 242.000 Da & $6,074 \pm 0,981 \mathrm{~A}$ & $2,675 \pm 2,977 \mathrm{~A}$ \\
\hline PNI 228.000 Da & $6,903 \pm 3,11 \mathrm{~A}$ & $7,396 \pm 3,024 \mathrm{~A}$ \\
\hline PNI 222.000 Da & $17,477 \pm 5,636 \mathrm{~A}$ & $15,946 \pm 11,647 \mathrm{~A}$ \\
\hline PNI 212.000 Da & $12,011 \pm 4,785 \mathrm{~A}$ & $14,310 \pm 6,156 \mathrm{~A}$ \\
\hline PNI 204.000 Da & $3,291 \pm 2,32 \mathrm{~A}$ & $7,738 \pm 10,142 \mathrm{~A}$ \\
\hline PNI 195.000 Da & $29,799 \pm 13,662 \mathrm{~A}$ & $26,370 \pm 8,137 \mathrm{~A}$ \\
\hline PNI $149.000 \mathrm{Da}$ & $49,869 \pm 14,221 \mathrm{~A}$ & $35,904 \pm 8,151 \mathrm{~B}$ \\
\hline PNI $137.000 \mathrm{Da}$ & $42,586 \pm 10,905 \mathrm{~A}$ & $31,497 \pm 11,374 \mathrm{~B}$ \\
\hline PNI 127.000 Da & $6,231 \pm 1,49 \mathrm{~A}$ & $5,092 \pm 2,479 \mathrm{~A}$ \\
\hline PNI $121.000 \mathrm{Da}$ & $19,282 \pm 8,017 \mathrm{~A}$ & $17,871 \pm 8,780 \mathrm{~A}$ \\
\hline PNI 116.000 Da & $8,954 \pm 1,762 \mathrm{~A}$ & $9,141 \pm 2,719 \mathrm{~A}$ \\
\hline PNI 101.000 Da & $9,294 \pm 2,025 \mathrm{~A}$ & $9,442 \pm 2,037 \mathrm{~A}$ \\
\hline PNI 45.000 Da & $10,265 \pm 2,659 \mathrm{~A}$ & $10,821 \pm 3,656 \mathrm{~A}$ \\
\hline PNI 42.000 Da & $66,965 \pm 32,92 \mathrm{~A}$ & $46,471 \pm 26,411 \mathrm{~A}$ \\
\hline PNI $31.000 \mathrm{Da}$ & $10,841 \pm 5,245 \mathrm{~A}$ & $16,041 \pm 6,762 \mathrm{~A}$ \\
\hline PNI 25.000 Da & $95,874 \pm 28,616 \mathrm{~A}$ & $93,705 \pm 40,933 \mathrm{~A}$ \\
\hline PNI 24.000 Da & $553,364 \pm 71,368 \mathrm{~A}$ & $466,454 \pm 56,505 B$ \\
\hline PNI 22.000 Da & ------- & $2,454 \pm 0,859$ \\
\hline PNI 20.000 Da & ------ & $13,806 \pm 18,949$ \\
\hline
\end{tabular}

250.729 Da. As médias dos pesos de cada proteína foram calculadas determinando os valores apresentados.

Para os animais deste ensaio, as imunoglobulinas identificadas foram IgA (166.000 Da), IgG de cadeia leve $(26.000 \mathrm{Da})$ e IgG de cadeia pesada (52.000 Da). Identificou-se as seguintes proteínas de fase aguda: Ceruloplasmina (107.000 Da), a1-glicoproteína ácida (38.000 Da) e Haptoglobina (39.000 Da). Observou-se a presença de Transferrina (86.000 Da), Hemopexina (79.000 Da) e $\alpha 1-$ antitripsina (56.000 Da), que embora sejam proteínas de fase agudas em bezeros, não são consideradas como tal em potros (Crisman et al. 2008). Identificou-se ainda a fração Albumina (62.000 Da). As demais proteínas encontradas não foram passíveis de identificação e, seu peso molecular em Daltons foi utilizado como referência.

As concentrações de IgA apresentaram significância obtida $(p<0,05)$ entre os grupos estudados, a média do G1 foi de $249,377 \mathrm{mg} / \mathrm{dL}$ enquanto a média do G2 foi de 197,550 mg/dL. Segundo Tizard (2002), os níveis séricos de IgA em equinos adultos hígidos é de $60-350 \mathrm{mg} / \mathrm{dL}$. Os valores de IGA observados demonstraram que, passada a fase neonatal inicial, onde há ingestão de colostro rico em imunoglobulinas, o sistema imunológico passa a trabalhar de maneira eficiente levando a uma estabilização dos teores séricos de IgA. Portanto, é possível que dentro desses valores ocorra variação conforme a faixa etária.

Não houve significância obtida $(p<0,05)$ entre os grupos estudados nas concentrações médias de IgG de cadeia leve e 
IgG de cadeia pesada. Os valores de IgG para o G1 $757 \pm 119$ $\mathrm{mg} / \mathrm{dL}$ ), corroboram os valores encontrados por Kenzig et al. (2009) obtidos 3 meses após o nascimento $(999 \pm 639$ $\mathrm{mg} / \mathrm{dL}$ ) para potros da raça quarto de milha. Os anticorpos igG representam $80 \%$ das imunoglobulinas plasmáticas, sendo portanto os principais responsáveis pela imunidade contra patógenos (Dawson et al. 2010). A concentração mínima de IgG necessária para proteção do potro contra infecções depende de fatores inerentes aos patógenos presentes no meio ambiente e, estão relacionados ao manejo e ao estresse (McGuire et al. 1977, Rumbaugh et al. 1979, Koterba et al. 1990, Feitosa 1999). Estudos demonstram que potros com falha total na transferência de imunidade passiva apresentam concentração sérica de IgG inferior a 400 $\mathrm{mg} / \mathrm{dL}$. Já quando a falha é parcial, os valores podem variar de 400-800 mg/dL, sendo considerados como adequados na proteção do potro contra infecções, quando acima de $800 \mathrm{mg} / \mathrm{dL}$ (Rumbaugh et al. 1979, Mellor \& Stafford 2004, Kenzig et al. 2009). Considerando-se as concentrações totais de IgG, os potros de ambos os grupos apresentaram valores adequados da mesma que, segundo Tizard (1998), é a mais importante imunoglobulina envolvida na resposta imune e de memória, demonstrando que a transferência de imunidade passiva ocorreu com sucesso na fase neonatal nos potros estudados. Assim, os animais apresentavam-se clinicamente sadios na fase perinatal.

As proteínas do leite são matéria prima para a síntese de componentes do sistema imunológico, como as imunoglobulinas. Após o desmame, a fonte de aminoácidos e proteínas provem exclusivamente de outros alimentos, sendo maiores as perdas durante o processo digestivo (Chavatte 1997). Suspeita-se que a diferença nas concentrações de IgA encontrada entre os grupos, deva-se à recente ingestão de leite pelos potros do G1. Porém o mesmo comportamento não foi observado nas concentrações de igG.

Embora tenha sido observada diferença $(p<0,05)$ nas concentrações de IgA entre os grupos, ambos apresentavam valores considerados basais para equinos adultos sadios, assim como para as concentrações de IgG. Baseado nos dados obtidos, constatou-se que o processo de imunidade celular apresentou-se maduro nos potros avaliados durante a fase perinatal. Tal achado nos leva a crer que o amadurecimento do processo celular de imunidade, se dá em um período que vai da fase neonatal, com a ingestão de colostro, até o desmame na fase perinatal.

A albumina é a proteína sérica de maior concentração determinada em equinos normais por meio de eletroforese. Tal proteína é responsável por $75 \%$ a $80 \%$ da pressão oncótica coloidal plasmática (Griffel \& Kaufman 1992), portanto as altas concentrações observadas em ambos os grupos são justificáveis. Segundo Axon \& Palmer (2008) a concentração de albumina sérica em potros permanece constante mesmo após a ingestão do colostro. No presente estudo, as concentrações de albumina estavam entre 55\% a $58 \%$ dos valores obtidos para proteínas séricas totais, superando a concentração de $50 \%$ considerada normal para equinos sadios (Kaneko et al. 1997).

Dentre as proteínas de fase aguda identificadas, observou-se diminuição $(p<0,05)$ nas concentrações de a1-glico- proteína ácida no G2, quando comparado ao G1. As proteínas de fase aguda são sintetizadas no fígado em resposta às citocinas inflamatórias (Wicher \& Dieppe 1985, Heinrich et al. 1990). A elevação plasmática de tais proteínas pode indicar ativação da resposta inflamatória, embora os potros se apresentassem hígidos, como descrito anteriormente. Possivelmente alguma enfermidade subclínica acometeu indivíduos do G1, levando à diferença entre os grupos. Outras três proteínas (149.000 Da, $137.000 \mathrm{Da}, 24.000 \mathrm{Da})$, que não foram identificadas pelo perfil eletroforético, apresentaram tendência semelhante, porém não se pode afirmar que as mesmas sejam proteínas de fase aguda.

Relativamente ao maior valor $(\mathrm{p}<0,05)$ de transferrina observado no G1 em comparação ao G2, não se encontrou na literatura justificativas para tal elevação, embora se reconheça a importância da tranferrina no transporte de íons $\mathrm{Fe}^{3+}$ nos potros lactentes, quando o desenvolvimento é intenso amplificando as necessidades nutricionais (Kaneko et al. 1997).

Na comparação dos traçados eletroforéticos entre os grupos, constatou-se ainda duas proteínas $(22.000$ Da e $20.000 \mathrm{Da}$ ) no G2, não encontradas no proteinograma dos potros desmamados há um dia (G1). Estudos adicionais são necessários para a identificação de tais moléculas.

0 presente estudo avaliou potros no período perinatal, desmamados com 3 a 5 meses de idade, período considerado muito precoce para o desmame na maioria dos criatórios. Apesar de grande parte da literatura disponível para discussão dos dados apresentar o perfil eletroforético de equinos adultos ou potros no período neonatal, os valores protéicos séricos obtidos neste ensaio demonstraram que a imunidade celular encontra-se estabelecida na fase perinatal, nos animais que ingeriram adequadamente colostro e leite. Assim, os dados apresentados poderão orientar o estabelecimento de metas de desmame precoce para equinos da raça Puro Sangue Árabe. Na escassez de literatura sobre o assunto em questão, consideramos que o presente trabalho poderá ainda contribuir com dados específicos do perfil protéico sérico de potros da raça Puro Sangue Árabe na fase perinatal, nunca antes reportados, podendo ser usados como referência para novos estudos.

\section{CONCLUSÕES}

0 presente estudo determinou diferenças no perfil protéico sérico de parâmetros relacionados à imunidade de equinos jovens imediatamente ao desmame, comparados com animais desmamados há mais de trinta dias. De acordo com os valores observados, concluiu-se que os animais mesmo desmamados precocemente, obtiveram transferência adequada de imunidade passiva.

Agradecimentos.- À FAPESP pelo apoio financeiro e institucional.

\section{REFERÊNCIAS}

Axon J.E \& Palmer J.E. 2008. Clinical pathology of the foal. Vet. Clin. Equine 24:357-385

Bierer B.W. 1969. Electrophoretic analysis of blood serum and plasma proteins of normal horses. Am. J. Vet. Res. 30:2237-2240.

Butler J.E. 1969. Bovine immunoglobulins: A review. J. Dairy Sci. 52:18951909. 
Chavatte P. 1997. Lactation in the mare. Equine Vet. Educ. 9:62-67.

Clabough D.L., Levine J.F., Grant G.L. \& Conboy H.S. 1991. Factors associated with failure of passive transfer of colostral antibodies in Standardbred foals. J. Vet. Intern. Med. 5:335-340.

Crisman M.V., Scarratt W.K. \& Zimmerman K.L. 2008. Blood proteins and inflammation in the horse. Vet. Clin. Equine 24:285-297.

Dawson T.R.M.Y., Horohov D.W., Meijer W.G. \& Muscatello G. 2010. Current understanding of the equine immune response to Rhodococcus equi. An immunological review of R. Equi pneumonia. Vet. Immunol. Immunopathol. 135:1-11.

Feitosa F.L.F. 1999. Importância da transferência da imunidade passiva para a sobrevivência de bezerros neonatos. Revta Educ. Contin. CRMVSP 2:17-22.

Feldman B.C., Zinkil J.G. \& Jain M.C. 2000. Veterinary Hematology. $5^{\text {th }}$ ed. Lippincott Williams and Wilkins, Philadelphia. 1344p.

Frey Jr F. 2006. Índices epidemiológicos em potros Puro Sangue Inglês, do nascimento até os seis meses de vida, na região de Bagé/RS. Dissertação de Mestrado, Universidade Federal de Pelotas, Pelotas, RS. 44p.

Griffel M.I. \& Kaufman B.S. 1992. Pharmacology of colloids and crystalloids. Crit. Care Clin. 8:235-253.

Heinrich P.C., Castell J.V. \& Andus, T. 1990. Interleukin-6 and the acute phase response. Biochem. J. 265:621-636.

Henneke D.R., Potter G.D., Krieder J.L. \& Yeats B.F. 1983. Relationship between body condition score, physical measurements and body fat percentage in mares. Equine Vet. J. 15:371-372.

Jainudeen M.R. \& Hafez E.S.E. 1995. Gestação, fisiologia pré-natal e parto, p.217-240. In: Hafez E.S.E. (Ed.), Reprodução Animal. $6^{a}$ ed. Manole, São Paulo. 582p.

Kaneko J.J., Harvey J.W. \& Bruss M.L. 1997. Clinical Biochemistry of Domestic Animal. $5^{\text {th }}$ ed. Academic Press, San Diego. 932p.

Kenzig A.R., O’Meara K.M., Kremer C.J., Jogan K.S., Colostral, Jack N.E. \& Cole K. 2009. Milk and serum immunoglobulin G concentrations in quarter horse mares and their foals. J. Eq. Vet. Sci. 29:486-487.

Knottenbelt D.C., Holdstock N. \& Madigan J.E. 2004. Neonatal syndromes: prematurity and dysmaturity, p.155-160. In: Holdstock N. \& Madigan J.E. Equine Neonatology Medicine and Surgery. Saunders, Philadelphia. 507p.

Koterba A.M., Drummond W.H. \& Kosh P.C. 1990. Equine Clinical Neonatology. Lea and Febiger, Philadelphia. 846p.

Kuhl J., Winterhoff N., Wulf M., Schweigert F.J., Schwendenwein I., Bruckmaier R.M., Aurich J.E., Kutzer P. \& Aurich C. 2011. Changes in faecal bacteria and metabolic parameters in foals during the first six weeks of life. Vet. Microbiol. 151:321-328.

Laemmli U.K. 1970. Cleavage of structural proteins during the assembly of the head of bacteriophage T4. Nature 227:680-685.

LeBlanc M.M., Tran T., Baldwin J.L. \& Pritchard E.L. 1992. Factors that influence passive transfer of immunoglobulins in foals. J. Am. Vet. Med. Assoc. 200:179-183.
Lima R.A.S., Shirota R. \& Barros G.S.C. 2006. Estudo do complexo do agronegócio cavalo. Centro de Estudos Avançados em Economia Aplicada (Cepea), ESALQ/USP. Relatório Final.66p.

McGuire T.C., Crawford T.B., Hallowell A.L. \& Macomber, L.E. 1977. Failure of colostral immunoglobulin transfer as an explanation for most infections and deaths of neonatal foals. J. Am. Vet. Med. Assoc. 170:13021304.

Mellor D.J. \& Stafford K.J. 2004. Animal welfare implications of neonatal mortality and morbidity in farm animals. Vet. J. 168:118-133.

Morris D.D. 1986. Immunologic diseases of foals. Comp. Cont. Educ. Pract. 8:S139-S150.

Paltrinieri S., Giordano A., Villani M., Manfrin M., Panzani S. \& Veronesi M.C. 2008. Influence of age and foaling on plasma protein electrophoresis and serum amyloid $A$ and their possible role as markers of equine neonatal septicaemia. Vet. Journal 176:393-396.

Parish S.M. 1996. Ruminant immunodeficiency diseases, p.1857-1860. In: Smith B.P. (Ed.), Large Animal Internal Medicine. $2^{\text {nd }}$ ed. Mosby, St Louis. 2040p.

Pfeiffer N.E., McGuire T.C., Bendel R.B. \& Welkel J.M. 1977. Quantitation of bovine immunoglobulins: comparison of single radial immunodiffusion, zinc sulfate turbidity, serum electrophoresis, and refractometer methods. Am. J. Vet. Res. 38:693-698.

Raidal S.L. 1996. The incidence and consequences of failure of passive transfer of immunity on a Thoroughbred breeding farm. Aust. Vet. J. 73:201-206.

Raidal S.L., McTaggart C. \& Penhale J. 2005. Effect of withholding macromolecules on the duration of intestinal permeability to colostral IgG in foals. Aust. Vet. J. 83:78-81.

Rumbaugh G.E., Ardans A.A., Ginno D. \& Trommershausen-Smith A. 1979 Identification and treatment of colostrum-deficient foals. J. Am. Vet. Med. Assoc. 174: 273-276.

Rossdale P.D. \& Ricketts S.W. 1979. Medicina práctica en el haras. Editorial Hemisferio Sur, Buenos Aires. 464p.

Scotoni C.M.M. \& Neto R.M. 1991. Transferência de imunidade passiva em equinos: comportamento imunológico do recém-nascido. Anais ESALQ Piracicaba, 48:109-126.

Stelwagen K., Carpenter E., Haigh B., Hodgkinson A. \& Wheeler T.T. 2009. Immune components of bovine colostrum and milk. J. Anim. Sci. 87:3-9.

Stoneham S.J., Digby N.J. \& Ricketts, S.W. 1991. Failure of passive transfer of colostral immunity in the foal: incidence, and the effect of stud management and plasma transfusions. Vet. Rec. 128:416-419.

Taylor F.G.R. \& Hillyer M.H. 1997. Diagnostic Techniques in Equine Medicine. W.B. Saunders, London. 348p.

Tizard I.R. 1998. Imunologia Veterinária. 5a ed. Roca, São Paulo. 726p.

Tizard I.R. 2002. Imunologia Veterinária. 6ª ed. Roca, São Paulo. 532p.

Wicher J.T. \& Dieppe P.A. 1985. Acute phase proteins. Clin. Immunol. Allergy 5:425-446. 